\title{
Evaluation of accelerometer mechanical filters on submerged cylinders near an underwater explosion
}

\author{
G. Yiannakopoulos * and P.J. van der Schaaf \\ Defence Science and Technology Organisation, \\ Aeronautical and Maritime Research Laboratory, \\ GPO Box 4331, Melbourne, Victoria 3001, Australia
}

Received 30 May 1997

Revised 10 September 1998

An accelerometer, mounted to a structure near an explosion to measure elasto-plastic deformation, can be excited at its resonant frequency by impulsive stresses transmitted within the structure. This results in spurious high peak acceleration levels that can be much higher than acceleration levels from the explosion itself. The spurious signals also have higher frequencies than the underlying signal from the explosion and can be removed by a low pass filter. This report assesses the performance of four accelerometer and filter assemblies. The assessment involves measurements of the response of a mild steel cylinder to an underwater explosion, in which each assembly is mounted onto the interior surface of the cylinder. Three assemblies utilise a piezoresistive accelerometer in which isolation is provided mechanically. In the fourth assembly, a piezoelectric accelerometer, with a built-in filter, incorporates both mechanical and electronic filtering. This assembly is found to be more suitable because of its secure mounting arrangement, ease of use, robustness and noise free results.

\section{Introduction}

During acceleration measurements near an explosion, an accelerometer mounted directly on a thinwalled structure may be excited at its resonant frequency, resulting in spurious high peak acceleration levels. To prevent excitation of the accelerometer at resonance, a material with low pass filter character-

\footnotetext{
*Corresponding author. E-mail: george.yiannakopoulos@dsto. defence.gov.au.
}

istics can be inserted between the accelerometer and the surface under investigation. Another technique is to use electronic filtering, but this requires the accelerometer to have a higher dynamic range compared to using the accelerometer with a mechanical filter. Filtering also can be performed using computer software. This involves recording the spurious peak levels that are much higher than the signal from the explosion, so that the true signal is recorded at poor resolution. Furthermore, as the spurious peak levels cannot be predicted, there is the likelihood that they will clip on the recording instrumentation. Clipped signals cannot be filtered because the information lost may also contain frequency components from the true signal, and thus the true signal cannot be fully recovered.

This study assesses the suitability of four filter assemblies to record the high peak, high bandwidth acceleration signal typical on a structure exposed to an underwater explosion. The assemblies were attached inside a submerged cylinder at the same depth as the charge, which was detonated nearby. The accelerometers were mounted in an orientation so that the accelerometer axis of measurement was in the direction of shock wave propagation. This configuration was chosen to minimise accelerometer cross-axis sensitivity error, which can also result in spurious levels as reported by [4, pp. 73-97].

The four filter assemblies evaluated consisted of:

(i) A piezoelectric accelerometer with a built-in mechanical and electronic filter;

(ii) A piezoresistive accelerometer attached, by an adaptor, to a commercial mechanical filter pad;

(iii) A piezoresistive accelerometer as part of an integral commercial filter in which the accelerometer was sandwiched between two thin isolation pads;

(iv) A piezoresistive accelerometer enclosed in an aluminium housing sandwiched between two comparatively thicker pads consisting of bromo-butyl. 

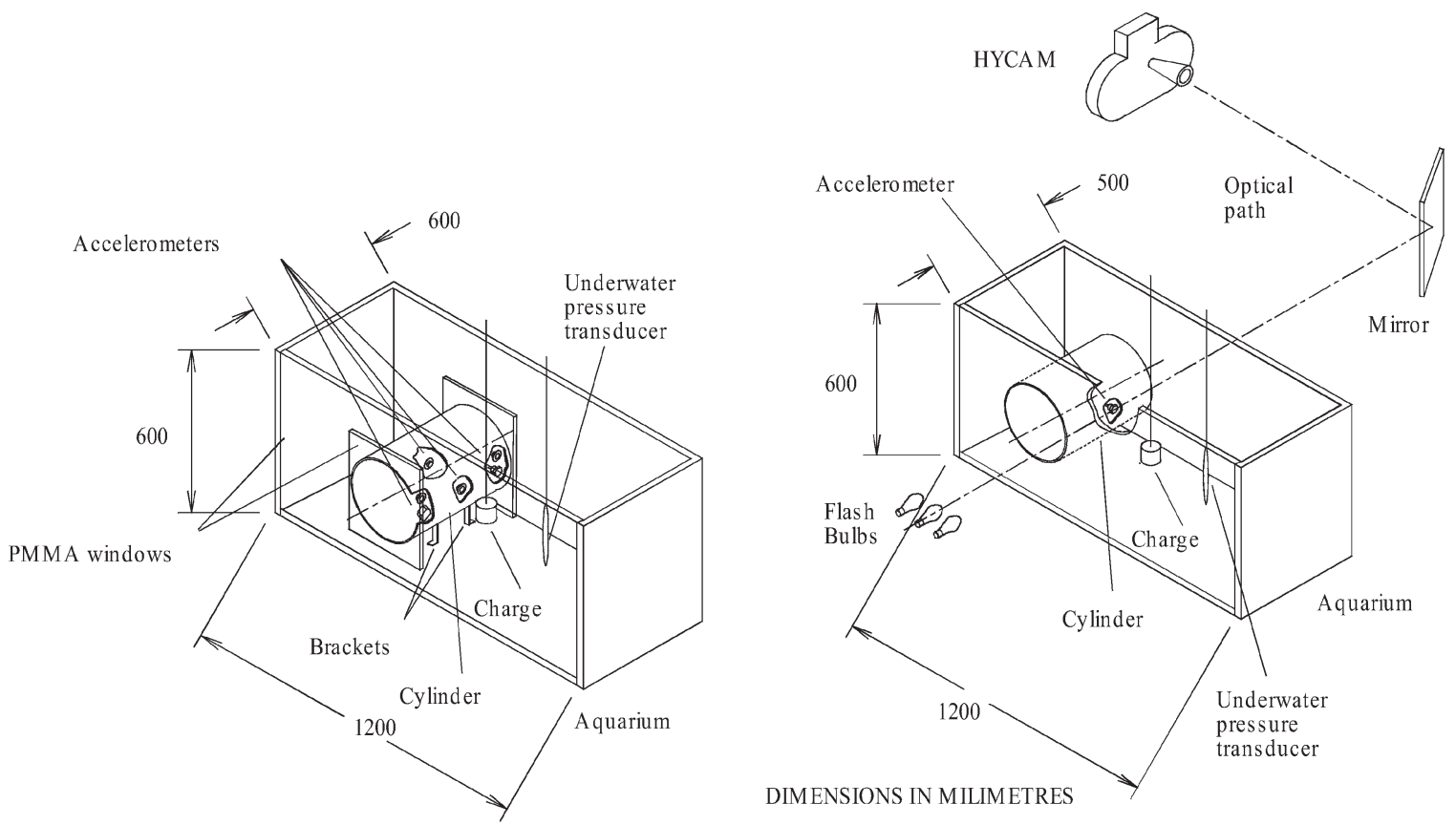

Fig. 1. Schematic of the aquarium and cylinder experimental set-ups for events $1-4$, left, and 5-7, right. Shown are the charge, pressure transducer and cutouts of the cylinder to indicate the accelerometer locations.

Table 1

Summary of characteristics of accelerometer and mechanical filter assemblies

\begin{tabular}{llcc}
\hline Accelerometer model & Abbreviation & Total mass (g) & Cut-off frequency (kHz) \\
\hline Endevco 7255A with built-in filter & $7255 \mathrm{~A}$ & 9 & 10 \\
Endevco 7270A in AMRL mechanical filter & $7270 \mathrm{~A}-\mathrm{AMRL}$ & 8 & $8^{*}$ \\
Endevco 7270A on Bruel \& Kjaer model UA-0559 mechanical filter & $7270 \mathrm{~A}-\mathrm{B} \& \mathrm{~K}$ & 26 & $9^{* *}$ \\
Endevco 7270A in Sandia mechanical filter & 7270 AM6 & 15 & 10 \\
\hline
\end{tabular}

* Determined from shaker at low acceleration levels (approximately $50 \mathrm{~g}$ peak to peak).

** Determined from B\&K data sheet (Bruel \& Kjaer UA-0559) and confirmed by a shaker at low acceleration levels.

The last design was developed at the Aeronautical and Maritime Research Laboratory (AMRL) to test different isolation materials.

\section{Experimental set-up}

The experimental configuration is shown in Fig. 1 and consisted of a cylinder in a wooden aquarium with a charge detonated nearby. Underwater pressure transducers recorded the free-field pressure. Accelerometers were mounted in the interior of the cylinder and measured the response of the cylinder to the shock wave. In Table 1 are summarised some of the more important characteristics of the four accelerometer filter assemblies. Accelerometer models Endevco 7255A and $7270 \mathrm{~A}$ were used for these investigations. The lightest assemblies are the $7255 \mathrm{~A}$ and the $7270 \mathrm{~A}$ AMRL.

A total of seven experiments were conducted, varying the stand-off distance and explosive mass. The stand-off distance, D, was measured between the accelerometer location closest to the charge, A3, and the centre of the cylindrical charge. The stand-off distance, charge mass and the different accelerometer models used during the experiments are presented in Table 2, in which each experiment is referred to as an event.

\subsection{Cylinder and aquarium}

The cylinder, $271 \mathrm{~mm}$ internal diameter and $500 \mathrm{~mm}$ in length, was fabricated by rolling a $2 \mathrm{~mm}$ thick mild steel sheet and welding the adjoining ends by a through-thickness weld. In events $1-4$, two brack- 
Table 2

Mass of explosive and stand-off distances for each event. The charge consisted of PE4

\begin{tabular}{|c|c|c|c|c|c|c|c|c|}
\hline \multirow[t]{2}{*}{ Event } & \multirow[t]{2}{*}{ Explosive mass (g) } & \multirow[t]{2}{*}{ Stand-off $D(\mathrm{~cm})$} & \multicolumn{6}{|c|}{ Accelerometer locations } \\
\hline & & & $\mathrm{A} 1$ & $\mathrm{~A} 2$ & A3 & A4 & A5 & A6 \\
\hline 1 & 10 & 15 & $7255 \mathrm{~A}$ & & 7270A-AMRL & & 7270A-AMRL & 7270A-AMRL \\
\hline 2 & 10 & 7.5 & & & $7255 \mathrm{~A}$ & & & 7270A-AMRL \\
\hline 3 & 10 & 7.5 & & & $7255 \mathrm{~A}$ & & & 7270A-AMRL \\
\hline 4 & 10 & 15 & $7255 \mathrm{~A}$ & 7270A-AMRL & 7270A-AMRL & 7270AM6 & 7270A-B\&K & 7270A-AMRL \\
\hline 5 & 5 & 30 & & & $7255 \mathrm{~A}$ & & & \\
\hline 6 & 5 & 15 & & & $7255 \mathrm{~A}$ & & & \\
\hline 7 & 5 & 10 & & & $7255 \mathrm{~A}$ & & & \\
\hline
\end{tabular}

ets screwed on the bottom of the cylinder, secured the cylinder to the bottom of the aquarium. The cylinder ends were sealed by square transparent polymethyl methacrylate (PMMA) sheets with the intention of recording the cylinder deformation using high speed photography. The PMMA sheets were $10 \mathrm{~mm}$ thick and suitably grooved to be attached to the ends of the cylinders. The optical clarity proved poor and this configuration required modifications for events 5-7 for which the cylinder ends were made to protrude through the aquarium wooden walls. In these later events streak photography monitored the displacement of the cylinder wall at location A3.

Bubble collapse, and hence pulsation, of the detonation products was prevented by designing the aquarium to disintegrate upon the impact of the incident shock wave. Therefore the study was confined to the deformation arising from the shock wave.

\subsection{Charge and experimental configuration}

The charge consisted of plastic explosive, PE4, encased in a PMMA cylindrical container, to which an Exploding Bridge Wire detonator was attached on the top surface in contact with the PE4. The PMMA container formed a right cylinder with its height equal to its diameter.

The charge was detonated at distances of $7.5,10$, 15 and $30 \mathrm{~cm}$ from the cylinder surface. PCB model 138A underwater pressure transducers were positioned on the opposite side of the charge to the cylinder and recorded the free-field pressure at the same stand-off distance from the explosive.

\subsection{Accelerometers and mounting}

The 7255A, shown in Fig. 2, is a piezoelectric type with a built-in mechanical, see [2, Vol. I, pp. 71$80]$, incorporating a stud at the bottom for mounting.
A light twisted pair cable is attached to the top of the unit, soldered on two terminals. The transducer provides a low impedance output. The filter design incorporates both an internal electronic filter, of the low pass two pole Butterworth type, in combination with a matched spring and damping mount.

The Bruel and Kjaer model UA-0559 mechanical filter is also stud mounted, and consists of a thin metal shell filled with butyl rubber. A thin metal disc with a stud is adhered on the top of the rubber, decoupling it from the metal shell. An Endevco model 7270A accelerometer is mounted by an aluminium adaptor, which is screwed to the disc as shown in Fig. 3. The adaptor top face has a high surface finish and two M3 holes for securing the accelerometer. This mechanical filter design supports compression better than tension.

The AMRL filter consists of an aluminium housing that encapsulates two bromo-butyl isolation pads on the top and bottom of an Endevco piezoresistive 7270A accelerometer, forming a sandwich, as shown in Fig. 4. It was designed for measurements of walls undergoing explosive loading from internal air blast, as discussed in [5]. The accelerometer is held in place by the isolation pads, and is secured by the mating surface and housing, forming a tight fit. The assembly was mounted on the cylinder by three screws that were attached from the outside, with the nuts on the inside, and were torqued to $10 \mathrm{Nm}$.

The Endevco 7270AM6, Fig. 5, consists of an Endevco 7270A accelerometer sandwiched from the top and bottom by a thin elastomer sheet and enclosed by an aluminium housing. The accelerometer and mechanical filter assembly is mounted by a central threaded stud. This assembly was developed by the Sandia National Laboratory, see [1, Vol. I, pp. 273-292].

Assemblies 7255A and 7270AM6 were mounted on a thin wall adaptor, Fig. 6 , which was attached on the cylinder surface by three M3 screws. The adaptor was necessary because the cylinder thickness was too thin 


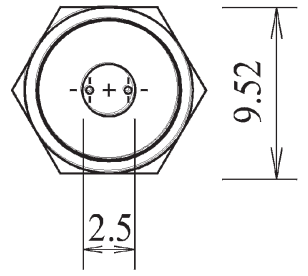

PLAN VIEW

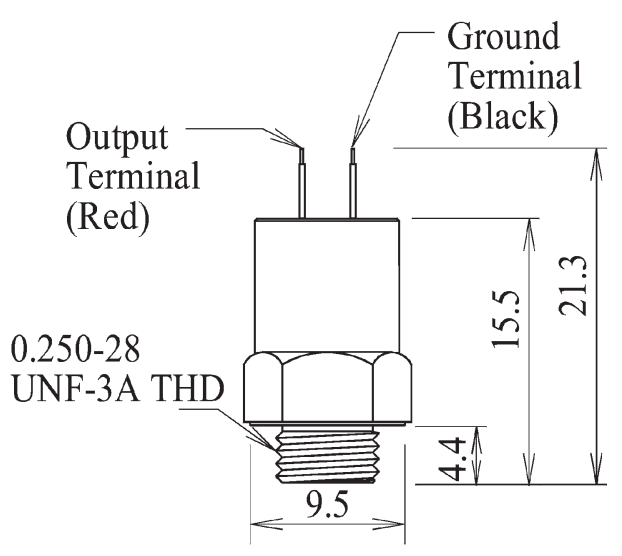

$\underline{\text { SIDE VIEW }}$

\section{DIMENSIONS IN MILLIMETRES}

Fig. 2. Detail of Endevco 7255A-01 accelerometer with built-in mechanical filter.

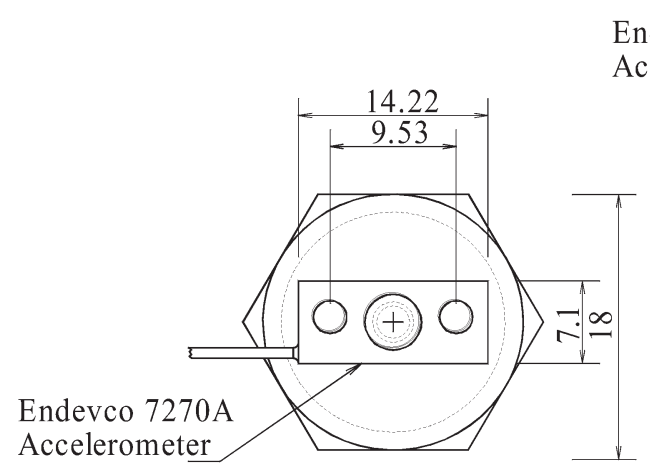

PLAN VIEW
Endevco $7270 \mathrm{~A}$

Accelerometer

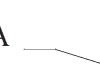

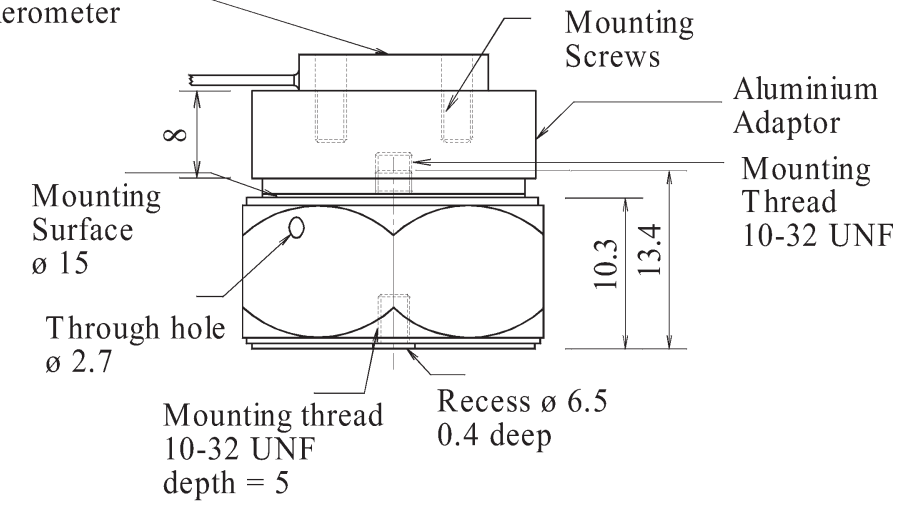

\section{$\underline{\text { SIDE VIEW }}$}

\section{DIMENSIONS IN MILLIMETRES}

Fig. 3. Detail of the 7270A-B\&K assembly.

for direct mounting. The cylinder was flattened slightly to accommodate the surface of the adaptor.

The locations of the accelerometers on the cylinder are shown in Fig. 7, and the stand-off distances for each event are shown in Table 2.

\subsection{Recording instrumentation}

The recording instrumentation consisted of ATS Digistar III self-recording units. The units provide signal conditioning and supply excitation current to the transducers. The recorders have provision for attaching either a piezoelectric coaxial connection or a four core shielded piezoresistive cable. Sampling was at 12bit resolution at a $5 \mathrm{MHz}$ sample frequency. The firing unit provided a pulse to externally trigger the recorders and mark time zero of the event.

\section{Results}

\subsection{Pressure-time profiles}

Typical free field pressure measurements are presented in Fig. 8 from the $10 \mathrm{~g}$ charge at stand-off distances of 7.5 and $15 \mathrm{~cm}$. The reflected shock wave from 


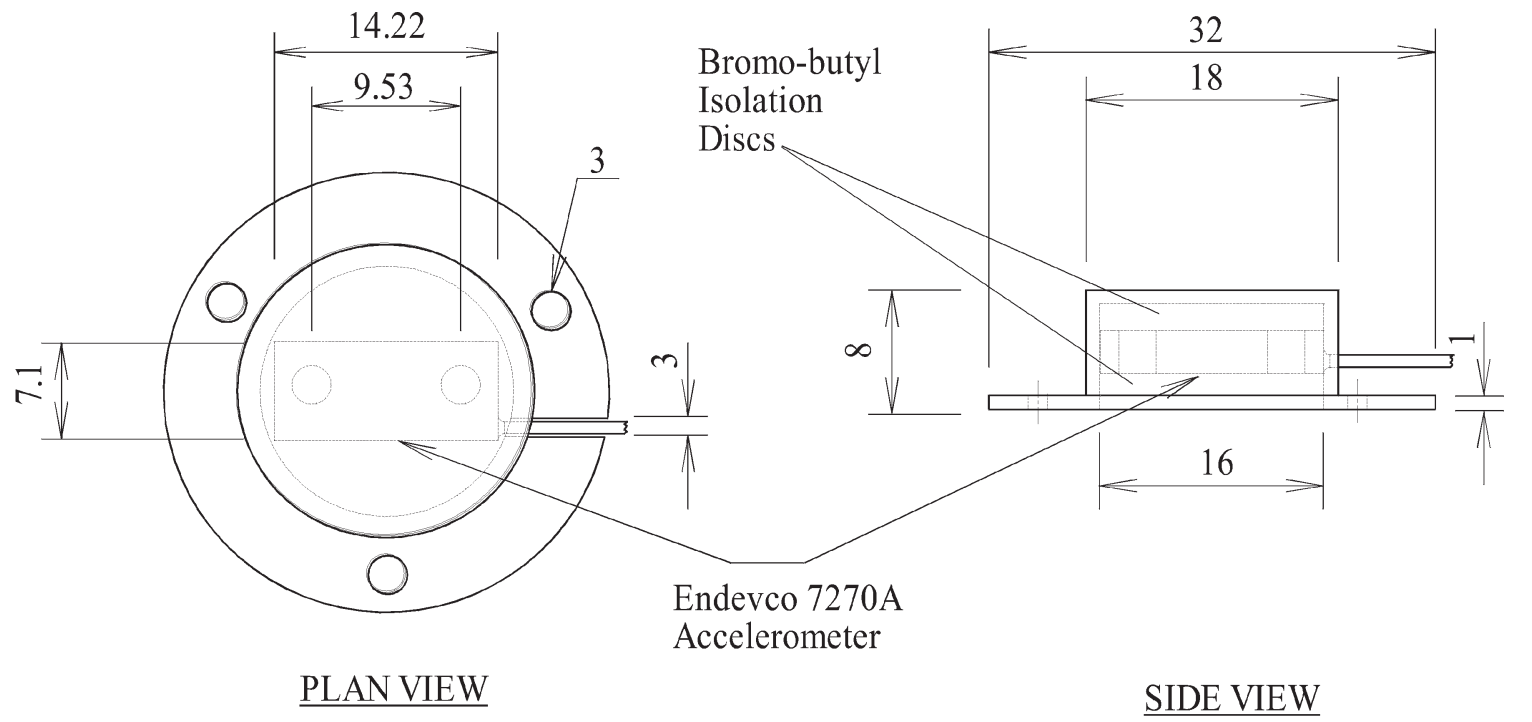

\section{DIMENSIONS IN MILLIMETRES}

Fig. 4. Detail of the 7270A-AMRL assembly.

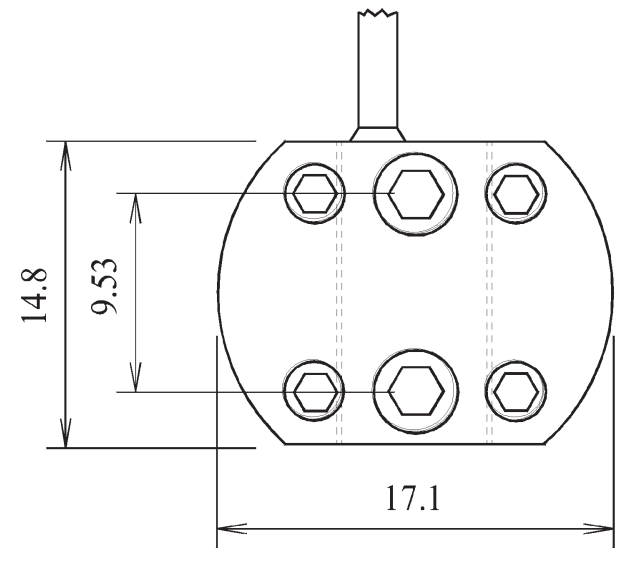

PLAN VIEW

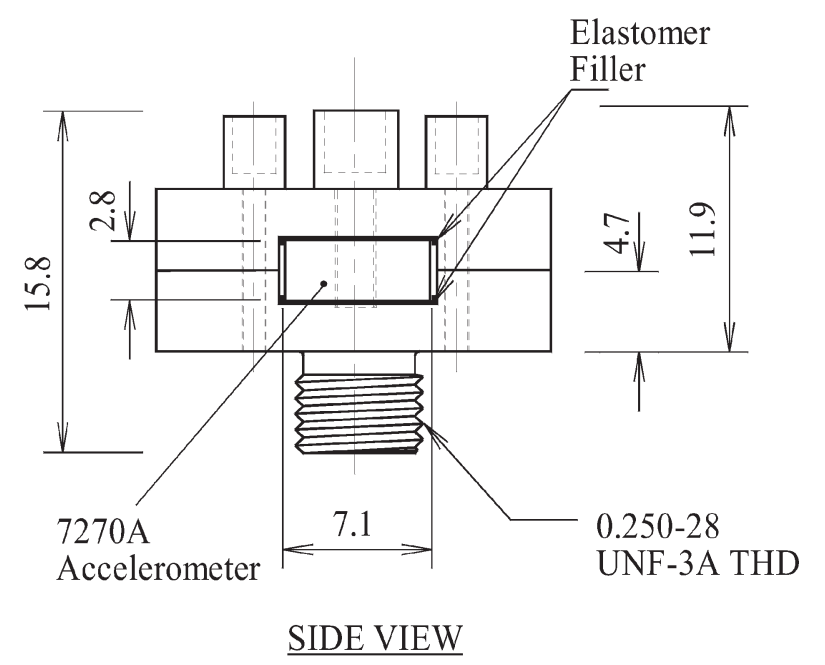

DIMENSIONS IN MILLIMETRES

Fig. 5. Detail of the Endevco 7270AM6 assembly.

the cylinder is annotated on the profiles, which is very sharp.

\subsection{Acceleration records}

Peak values of acceleration are summarised in Table 3 . The highest acceleration was obtained at location A3 for event 2 and was greater than $87,000 \mathrm{~g}$. For events $1-3$, peak accelerations proved higher than anticipated, exceeding the recorder's over-range setting. Times of arrival are given in Table 4, ranging from around $40 \mu \mathrm{s}$ for $10 \mathrm{~g}$ of PE4 at the $7.5 \mathrm{~cm}$ stand-off, and $200 \mu \mathrm{s}$ for $5 \mathrm{~g}$ at $30 \mathrm{~cm}$.

Acceleration-time profiles are presented in four groups, as shown in Figs 9-12, grouped according to the accelerometer locations. The first group, which is 


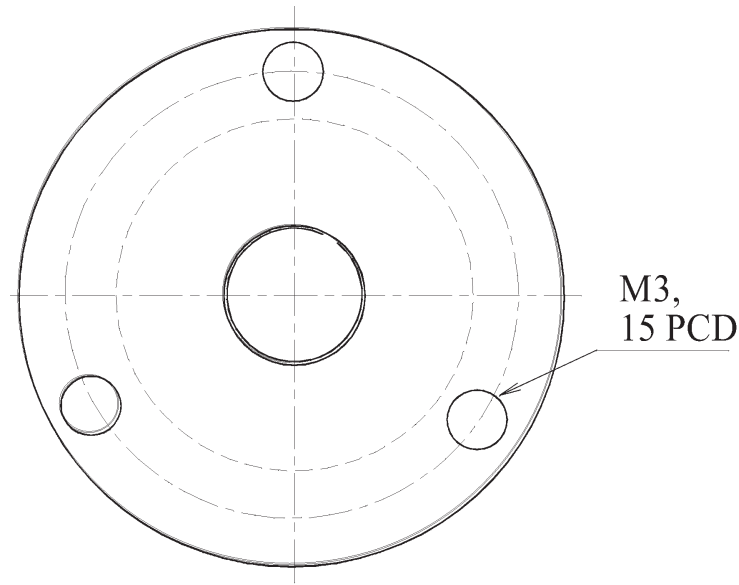

$\underline{\text { PLAN VIEW }}$

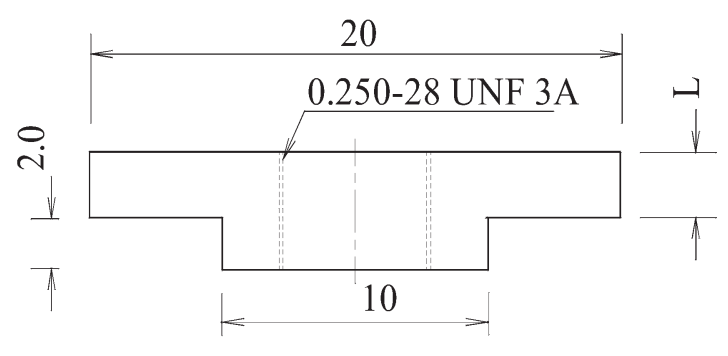

SIDE VIEW

MATERIAL: ALUMINIUM

DIMENSIONS IN MILLIMETRES

Fig. 6. Thin wall accelerometer mount adaptor for the 7255A and 7270AM6 assemblies.

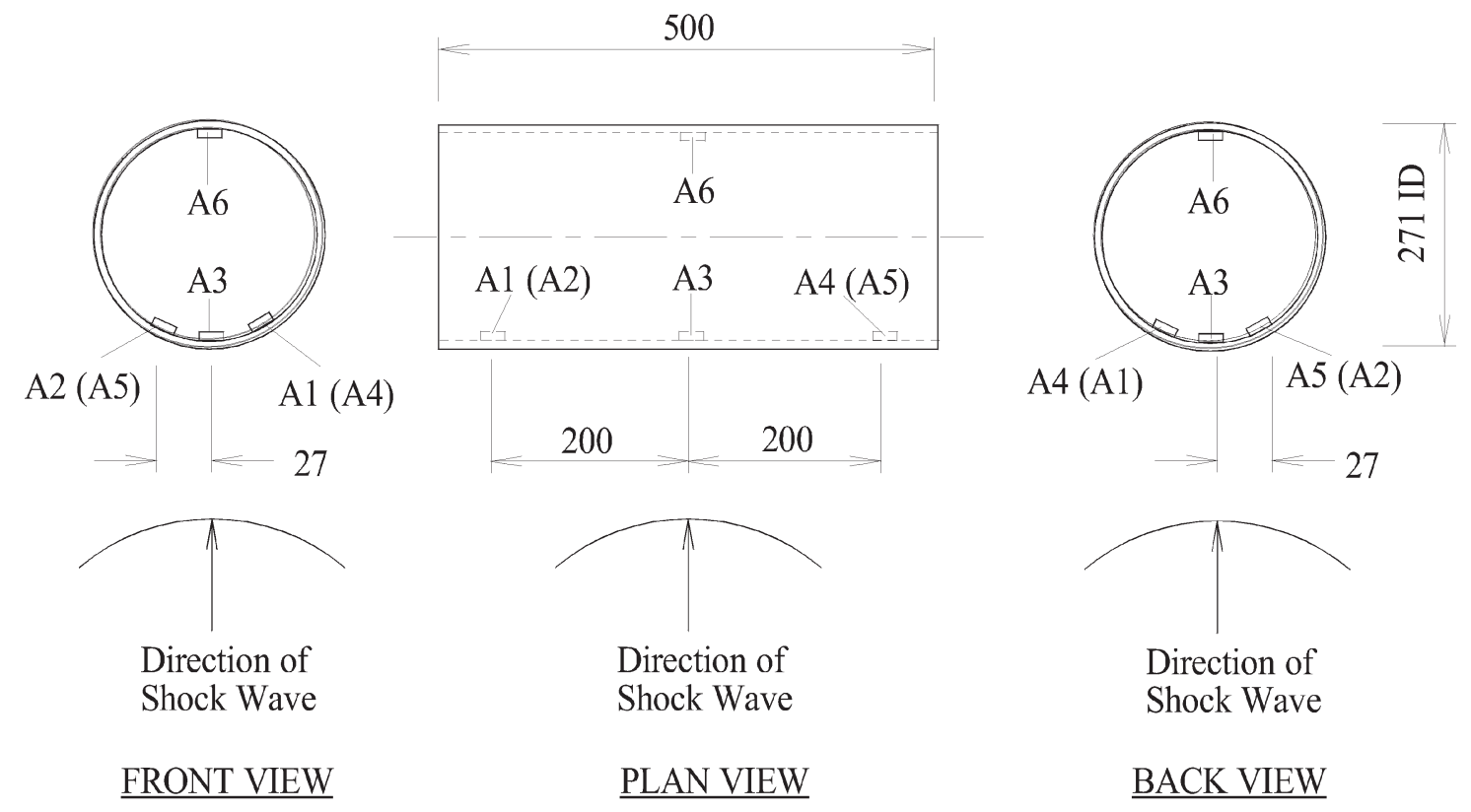

\section{DIMENSIONS IN MILLIMETRES}

Fig. 7. Detail of accelerometer locations. Accelerometers in parenthesis are hidden from view.

shown in Fig. 9, presents results from a $10 \mathrm{~g}$ charge at two stand-off distances, at 7.5 and $15 \mathrm{~cm}$, for accelerometer location A6 that was located on the other side of the cylinder. The acceleration profiles indicate that both the $7255 \mathrm{~A}$ and the $7270 \mathrm{~A}-\mathrm{AMRL}$ assemblies were successful at this location. The peak accelerations are higher for the 7270A-AMRL assembly, as is expected because the mass of the mount is distributed over a greater surface, adding less mass at this location. High resonance is evident in the latter part of the signal 

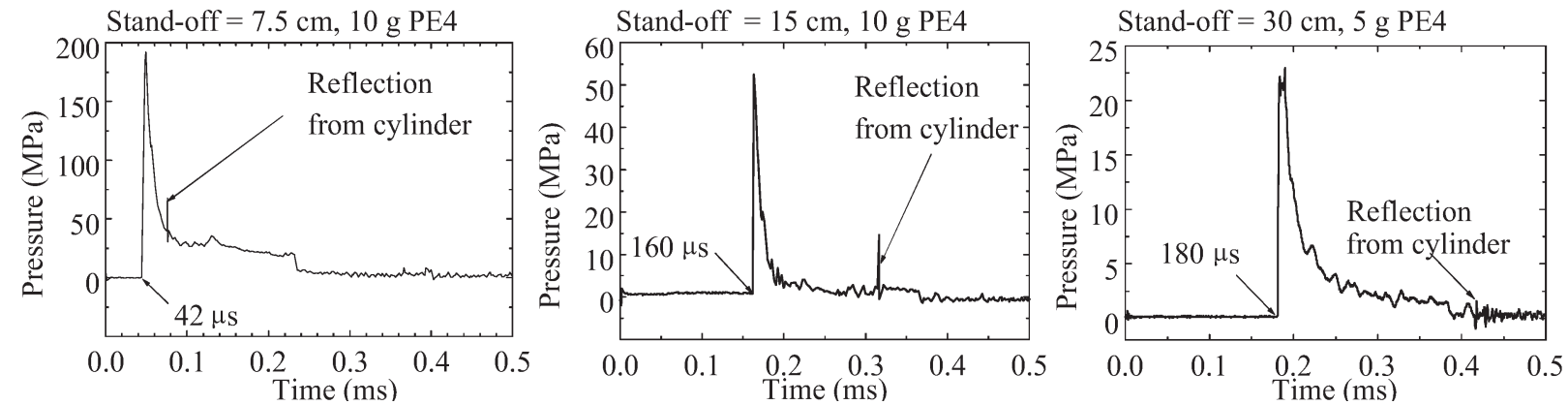

Fig. 8. Free field underwater pressure-time profiles at 7.5 and $15 \mathrm{~cm}$ stand-off distances for $10 \mathrm{~g}$ of PE4 explosive, and $30 \mathrm{~cm}$ for $5 \mathrm{~g}$ of PE4.
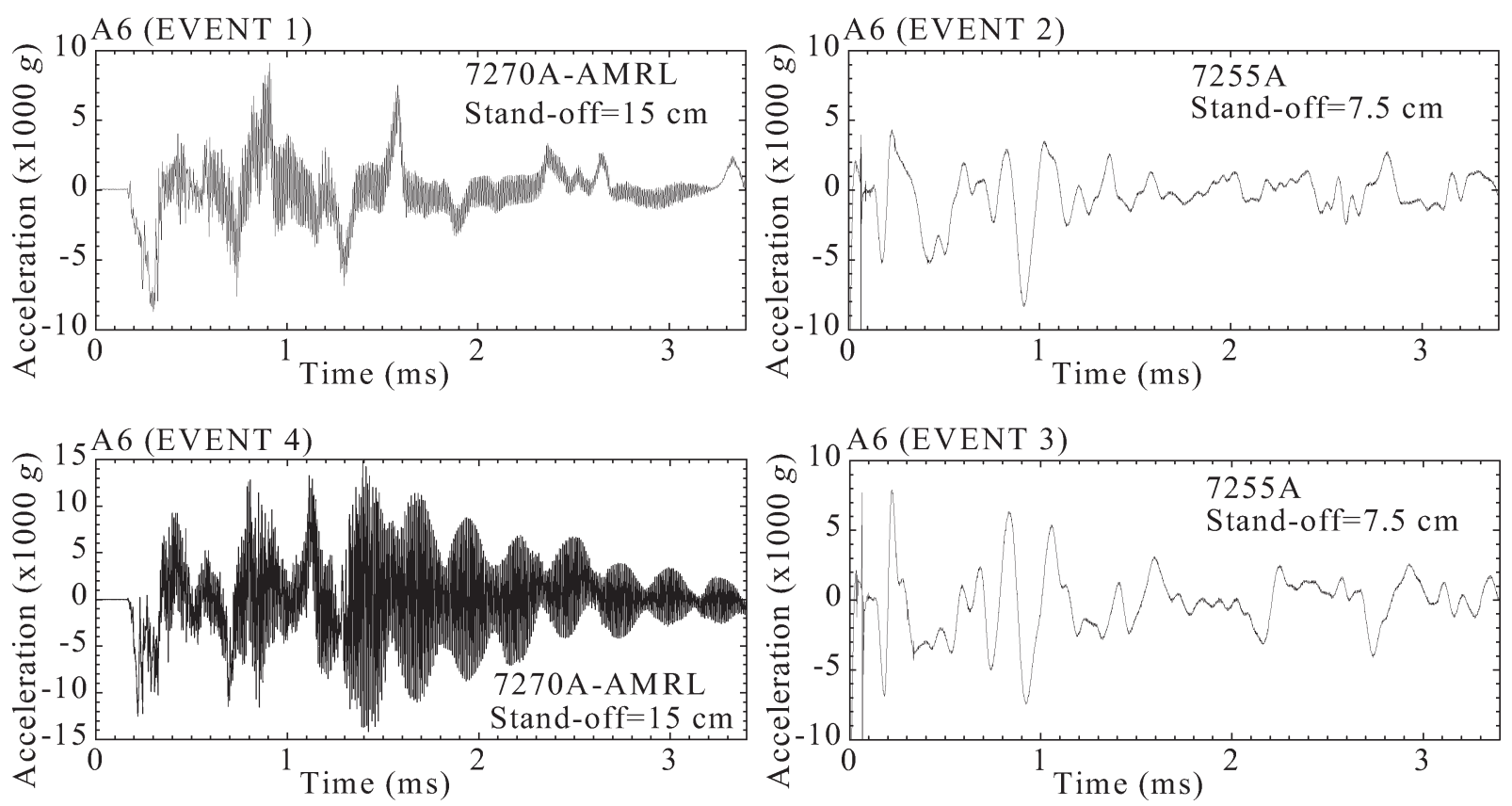

Fig. 9. Acceleration results for location A6 at 7.5 and $15 \mathrm{~cm}$ stand-off distances, from $10 \mathrm{~g}$ of PE4.

Table 3

Peak accelerations

\begin{tabular}{|c|c|c|c|c|c|c|c|}
\hline Event & $\begin{array}{c}D \\
(\mathrm{~cm})\end{array}$ & $\begin{array}{c}\mathrm{A} 1 \\
(g) \times 1000 \\
\end{array}$ & $\begin{array}{c}\mathrm{A} 2 \\
(g) \times 1000 \\
\end{array}$ & $\begin{array}{c}\mathrm{A} 3 \\
(g) \times 1000 \\
\end{array}$ & $\begin{array}{c}\mathrm{A} 4 \\
(g) \times 1000 \\
\end{array}$ & $\begin{array}{c}\mathrm{A} 5 \\
(g) \times 1000 \\
\end{array}$ & $\begin{array}{c}\text { A6 } \\
(g) \times 1000 \\
\end{array}$ \\
\hline 1 & 15 & $>23 /-17$ & & Accel. Failure & & Accel. Failure & $-8.7 / 9.1$ \\
\hline 2 & 7.5 & & & $>87 /-17$ & & & $-8 / 4.2$ \\
\hline 3 & 7.5 & & & Mount Failure & & & $-7 / 8$ \\
\hline 4 & 15 & $50 /-15$ & Accel. Failure & Accel. Failure & Accel. Failure & Accel. Failure & $-12 / 13$ \\
\hline 5 & 30 & & & $33 /-24$ & & & \\
\hline 6 & 15 & & & $67 /-36$ & & & \\
\hline 7 & 10 & & & $77 /-32$ & & & \\
\hline
\end{tabular}

from event 4. This resonance has been observed intermittently in previous measurements involving only the Endevco $7270 \mathrm{~A}$ accelerometer. It is thought to arise from stresses transmitted at the cable and accelerometer joint. A spike is observed prior the acceleration signal for the 7255A results. This is due to EMF pick-up 
Table 4

Shock wave arrival times

\begin{tabular}{cccccccc}
\hline Event & $D(\mathrm{~cm})$ & $\mathrm{A} 1(\mu \mathrm{s})$ & $\mathrm{A} 2(\mu \mathrm{s})$ & $\mathrm{A} 3(\mu \mathrm{s})$ & $\mathrm{A} 4(\mu \mathrm{s})$ & $\mathrm{A} 5(\mu \mathrm{s})$ & $\mathrm{A} 6(\mu \mathrm{s})$ \\
\hline 1 & 15 & 163 & & 90 & & 165 & 166 \\
2 & 7.5 & & & 37 & & & 131 \\
3 & 7.5 & & & 44 & & & 140 \\
4 & 15 & 153 & 149 & 88 & $144(122)$ & 156 & 168 \\
5 & 30 & & & 194 & & & \\
6 & 15 & & & 98 & & & \\
7 & 10 & & & 74 & & & \\
\hline
\end{tabular}
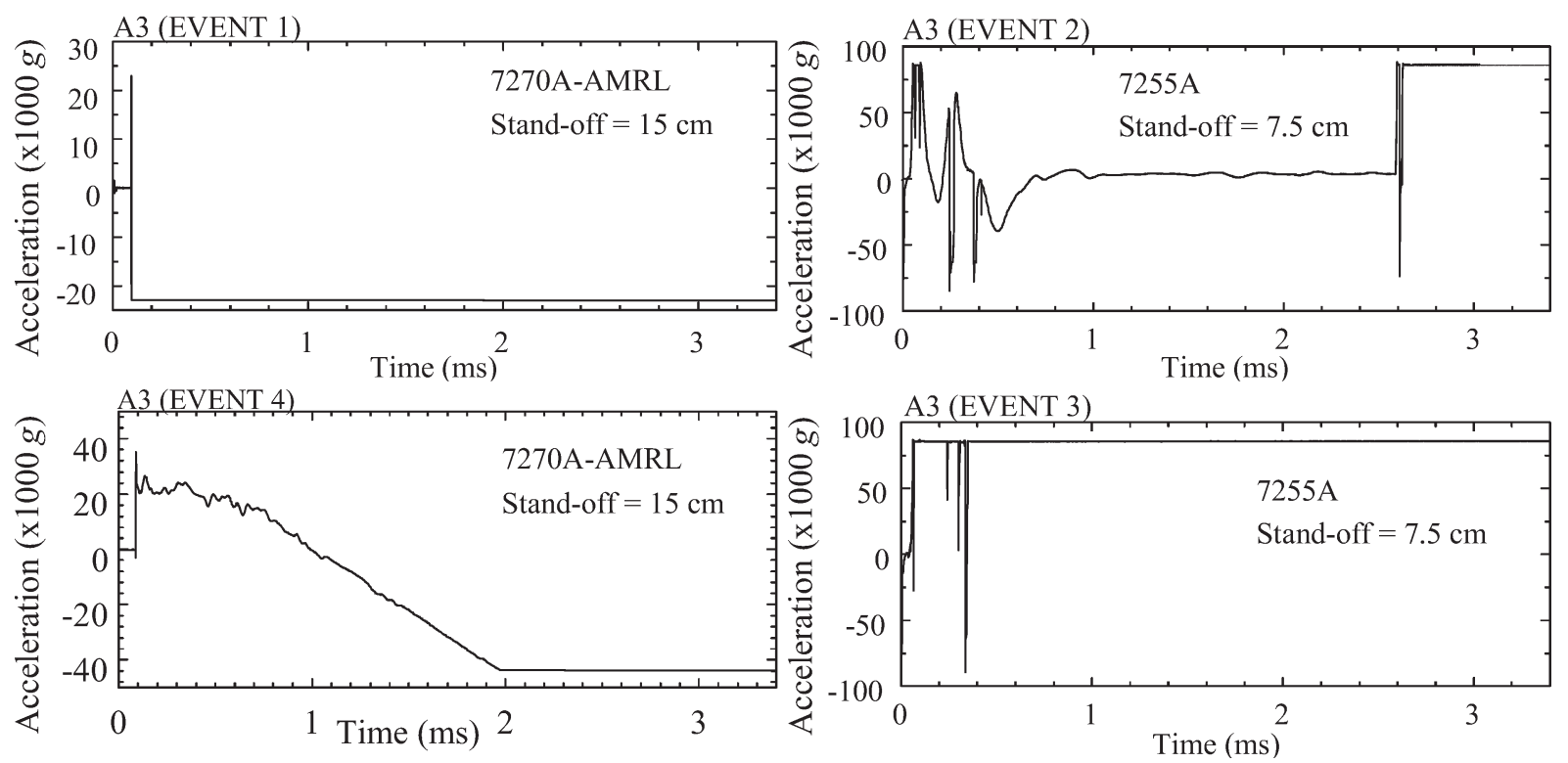

Fig. 10. Acceleration results for location A3 at 7.5 and $15 \mathrm{~cm}$ stand-off distances, from $10 \mathrm{~g}$ of PE4.

from the explosion and high voltage firing unit.

In Fig. 10 is presented the second group, location $\mathrm{A} 3$, where the accelerometers are 7.5 and $15 \mathrm{~cm}$ from a $10 \mathrm{~g}$ charge and at the location closest to the charge. The 7270A-AMRL assembly has failed in the two events shown. Although the records from the $7255 \mathrm{~A}$ are also unsatisfactory, there is more detail in the profiles. At these high acceleration levels this accelerometer generates a signal in excess of $10 \mathrm{~V}$, which is much greater than the over-range of the analogue to digital converter on the recorder, hence causing clipping. This suggests that the accelerometer may not have failed, but the results are not conclusive.

The third group, shown in Fig. 11, presents results for events 1 and 4 from locations A1, A2, A4 and A5. A $10 \mathrm{~g}$ charge was positioned $15 \mathrm{~cm}$ from location A3. These transducers are all $25 \mathrm{~cm}$ from the charge. High frequencies have been transmitted to the 7270AAMRL and 7270A-B\&K assemblies, resulting in ex- cessive accelerations that have caused the accelerometers to fail. High frequencies have also been transmitted to the 7270AM6 assembly, but the effect is less severe, causing high spurious peak accelerations that have resulted in clipping at the recorder. The record from the 7270AM6 assembly, Fig. 9, also exhibits similar resonance as observed from the 7270A-AMRL assembly. This record also shows a precursor wave at $122 \mu$ s after the explosion, followed by the shock wave in the water arriving at $144 \mu \mathrm{s}$. This is caused by wave transmission from location A3 through the steel cylinder at greater speed, thereby arriving before the slower direct shock wave through the water. This wave is recorded by all the accelerometers in this group, but it is particularly evident from the 7270AM6 result indicating that filtering has been totally ineffective.

The final group, shown in Fig. 12, presents accelerometer results from the $7255 \mathrm{~A}$ assembly at location A3 for a $5 \mathrm{~g}$ charge at stand-off distances of 10,15 

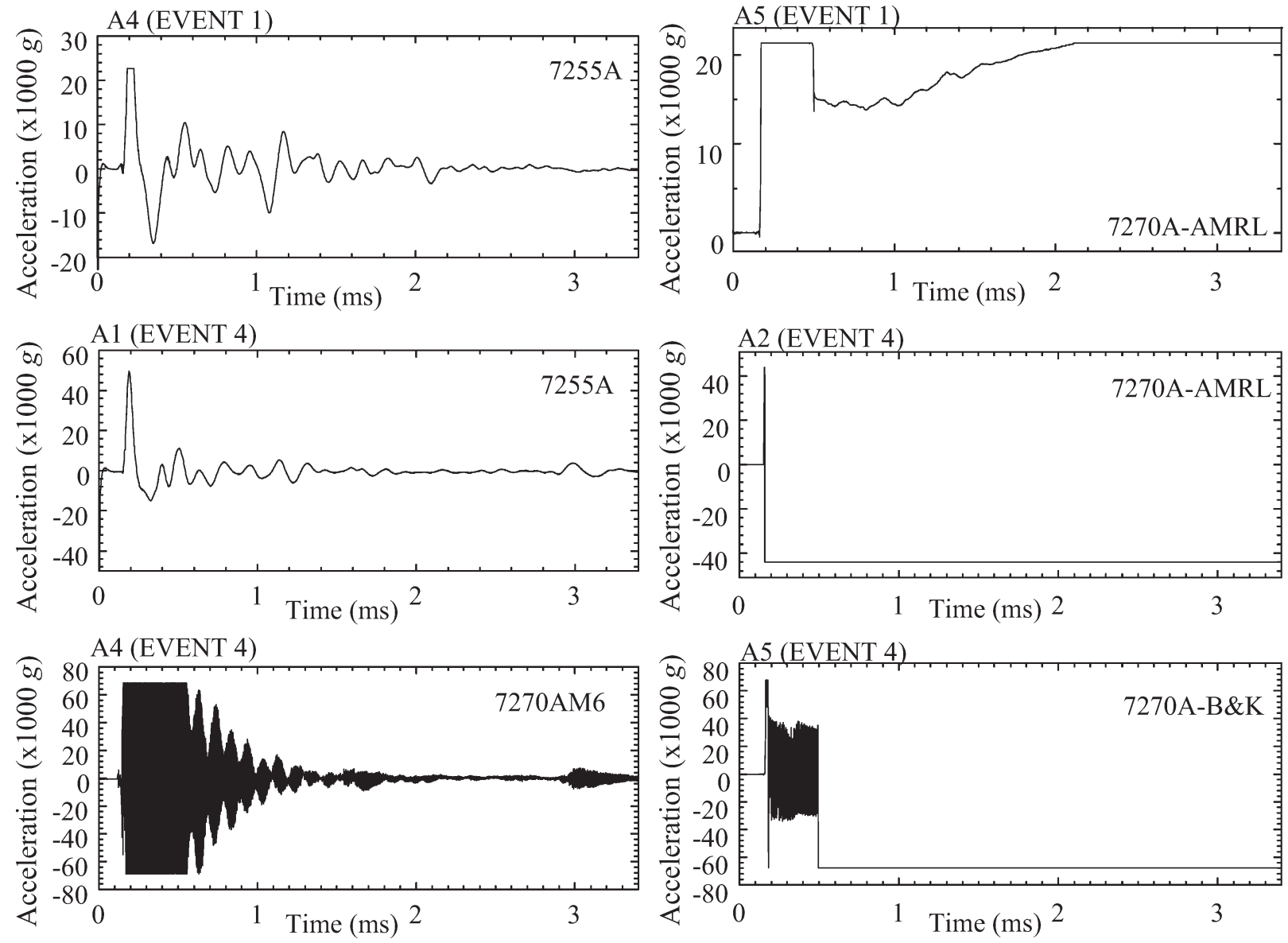

Fig. 11. Acceleration results for locations A1, A2, A4 and A5. The charge consisted of $10 \mathrm{~g}$ of PE4 located at $15 \mathrm{~cm}$ from location A3, that is the transducers were located $25 \mathrm{~cm}$ from the charge.

and $30 \mathrm{~cm}$ for events $5-7$. These events incorporated the modified cylinder configuration permitting streak photography measurements of the deformation of the cylinder. Figure 13 presents the streak obtained for the $10 \mathrm{~cm}$ stand-off distance, that is event 7 . Unfortunately this was the only useful record that was obtained from these measurements. Poor records were obtained for the other two events; for event 5 only slight deformation occurred and in event 6 the film broke as it was running up to speed.

\section{Discussion}

The results from a $10 \mathrm{~g}$ PE4 charge indicated that the cylinder was subjected to high peak accelerations, around $50,000 \mathrm{~g}$ for a $15 \mathrm{~cm}$ stand-off distance and greater than $87,000 \mathrm{~g}$ at $7.5 \mathrm{~cm}$. The detonation of a $5 \mathrm{~g}$ charge yielded accelerations that were not markedly lower, varying from $40,000 \mathrm{~g}$ for a $30 \mathrm{~cm}$ stand-off to $80,000 \mathrm{~g}$ for $10 \mathrm{~cm}$. The acceleration rise times are sharp, approximately $40 \mu \mathrm{s}$, which is comparable to the cut-off frequencies of all the accelerometer and filter assemblies tested.

The $7255 \mathrm{~A}$ assembly proved easy to mount and any cable breaks were quick to repair, involving simply soldering the leads. The design of the cable lead, connected to the top of the accelerometer, also proved advantageous for this application. In contrast, the Endevco 7270A accelerometer which has the lead attached to the side and in contact with the cylinder, permits stresses to be transmitted to the cable and accelerometer joint. It is thought that this is the cause of the high frequencies observed for the 7270AM6 and 7270AAMRL assemblies. Another disadvantage of this cable attachment configuration is that it is easy to shear the cable, as it is not protected by the assembly. Furthermore, repairs of the four core shielded cable were time consuming. 

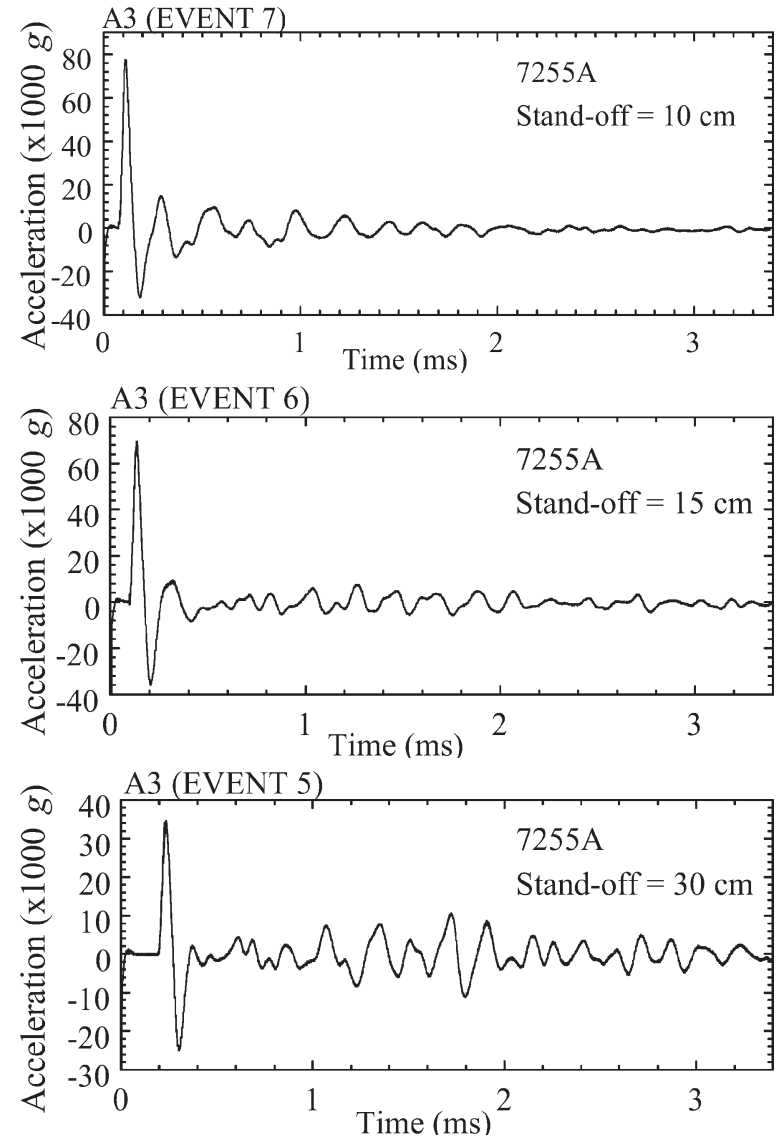

Fig. 12. Measurements at location A3 using $5 \mathrm{~g}$ of PE4 explosive, at 10,15 and $30 \mathrm{~cm}$ stand-off.

High frequencies were observed in all accelerometer records except for those from the 7255A assembly. The worst case, as has been noted, occurred for assembly 7270AM6 in event 4, Fig. 11, where the peak acceleration is much higher. This may have been caused from either improper installation of the assembly, or poor mechanical filter characteristics. Further investigations were not carried out because this assembly proved too heavy for this application and consequently was used sparingly. In particular, it was not considered suitable for the A3 location.

The thin wall adaptor proved effective but, during event 3 , at the $7.5 \mathrm{~cm}$ stand-off distance, the adaptor sheared at one of the M3 mount threads. Since these investigations were conducted, an improved adaptor has been constructed utilising more material at the threads for greater strength. The improved adaptor consists of a tripod configuration, rather than a circular disc, and consequently is lighter; see [6] for further details.

The accelerometer sensitivity values were obtained from calibrations provided by the manufacturer. An at-

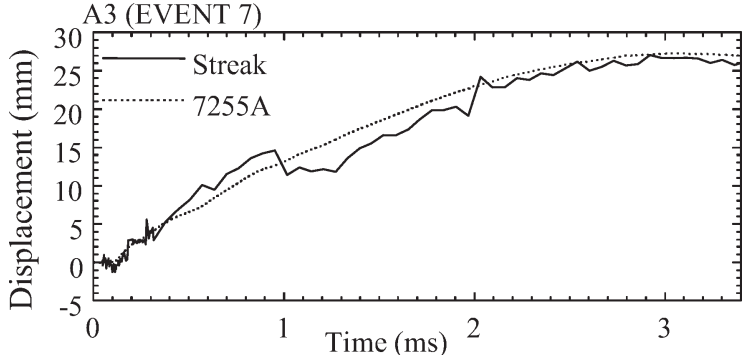

Fig. 13. Comparison, at the $10 \mathrm{~cm}$ stand-off distance, Event 7, between streak photography and displacement derived from the $7255 \mathrm{~A}$ assembly.

tempt was made to use streak photography to verify the sensitivity but this comparison proved too coarse due to the difficulty in identifying the poorly illuminated moving surface of the cylinder, as is indicated in Fig. 13 by the irregularities in the streak record. A further error arises from double integration of the acceleration record, caused by the inherent zeroshift error of a piezoelectric accelerometer, see [3, Vol. I, pp. 251269]. For the time window of interest, less than $4 \mathrm{~ms}$, zeroshift did not prove significant. A small offset was observed but this was taken to be constant. An average value was determined from a portion of the record after the shock wave, over a region in which no acceleration was considered present. The correction involved subtraction of the average offset from the acceleration record. With these considerations in mind, comparison between the results from streak photograph and the integrated acceleration shows good agreement.

The frequency response of each commercial filter assembly was obtained from the manufacturer's specifications. The equipment required for measuring higher acceleration levels was not readily available. For example, one technique reported involves applying an impulsive load by using a Hopkinson bar configuration, see [1, Vol. I, pp. 273-292]. Although a comparison was made from shaker table experiments, supporting the manufacturer's data, the peak accelerations proved very low, $0.05 \%$ of the peak accelerations measured. This technique was the only means available for determining the frequency response of the 7270AAMRL assembly.

The acceleration results have indicated that the rise time of the shock wave from the $7.5 \mathrm{~cm}$ stand-off distance is comparable to the rise times of the acceleration records. At shorter stand-off distances, sharper acceleration pulses are expected, so that there is a need for an assembly with a higher bandwidth, to at least $20 \mathrm{kHz}$. The $7255 \mathrm{~A}$ is an integral assembly and can- 
not be modified. For further development, the $7270 \mathrm{~A}$ is currently the most suitable accelerometer because of its light weight and high bandwidth. Together with the AMRL filter, whose characteristics can be improved by reducing its size, other shock isolation materials can be investigated to find a material with better damping characteristics. By the same reasoning, the 7270AM6 assembly also can be modified by using other materials. As previously noted, however, it proved too heavy for this application and the AMRL design appears to be the only configuration that can be developed further.

\section{Conclusion}

Investigations were conducted on different accelerometer low pass filters to evaluate their performance. These have considered the accelerometer and filter as a mechanical system consisting of a mount, the mechanical isolator and/or electronic filter, and the transducer. This modular construction proved flexible in meeting the measurement requirements for a deformable surface.

The results have shown that a piezoelectric accelerometer with a built-in mechanical and electronic filter is the most successful assembly in measuring the response of a thin-walled structure undergoing elastoplastic deformation. This is a consequence of the assembly's secure mounting arrangement, ease of use, robustness and noise free results. One reservation is the $10 \mathrm{kHz}$ cut-off frequency, but all other assemblies evaluated have this limitation.
The thin wall adaptor, which secured the accelerometer on the structure at three points, proved better than the stud mounted configuration.

\section{Acknowledgments}

The authors would like to thank Dr J.M. Brett and Dr N. Burman for their support. Mr T. Kinsey provided the streak photography.

\section{References}

[1] V.I. Bateman, R.G. Bell and N.T. Davie, Evaluation of shock isolation techniques for a piezoresistive accelerometer, in: Proc. 60th Shock and Vibration Symposium, 1989.

[2] A.S. Chu, Zeroshift of piezoelectric accelerometers in pyroshock measurements, in: Proc. 57th Shock and Vibration Symposium, 1986.

[3] A.S. Chu, Built-in mechanical filter in a shock accelerometer, in: Proc. 58th Shock and Vibration Symposium, 1988.

[4] D.W. Rockwell and J.D. Ramboz, Measurement of accelerometer transverse sensitivity, in: Proc. 35th Shock and Vibration Symposium, 1965.

[5] G. Yiannakopoulos, Internal pressure measurements from explosively loaded cubicles, 14th International Symposium on the Military Application of Blast Simulation, Las Cruces, New Mexico, 13-17 September 1995.

[6] G. Yiannakopoulos, An accelerometer adaptor for measurements of metal plate response from a near field explosive detonation, Review of Scientific Instruments 68(8) (August 1997), 3254-3255. 

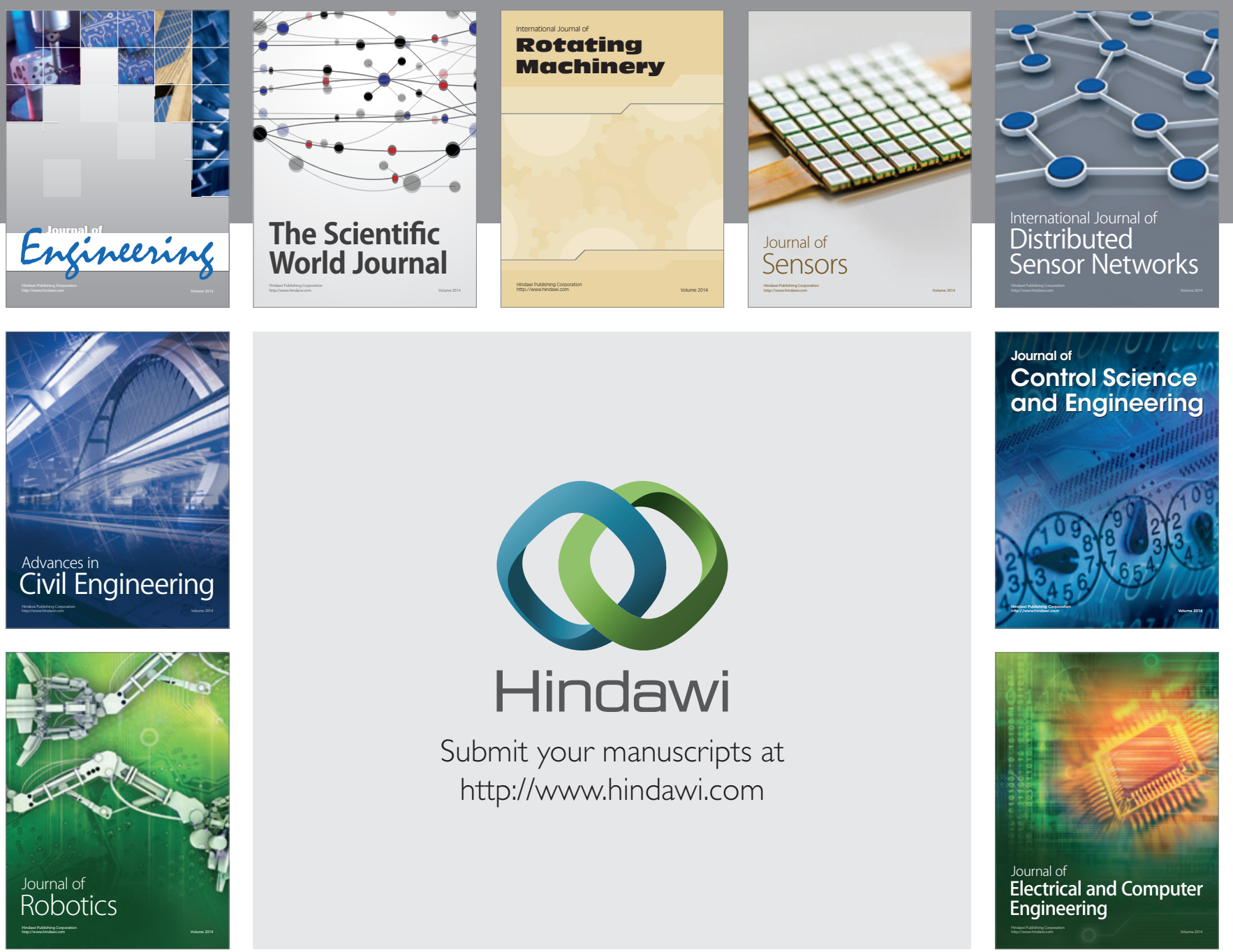

Submit your manuscripts at

http://www.hindawi.com
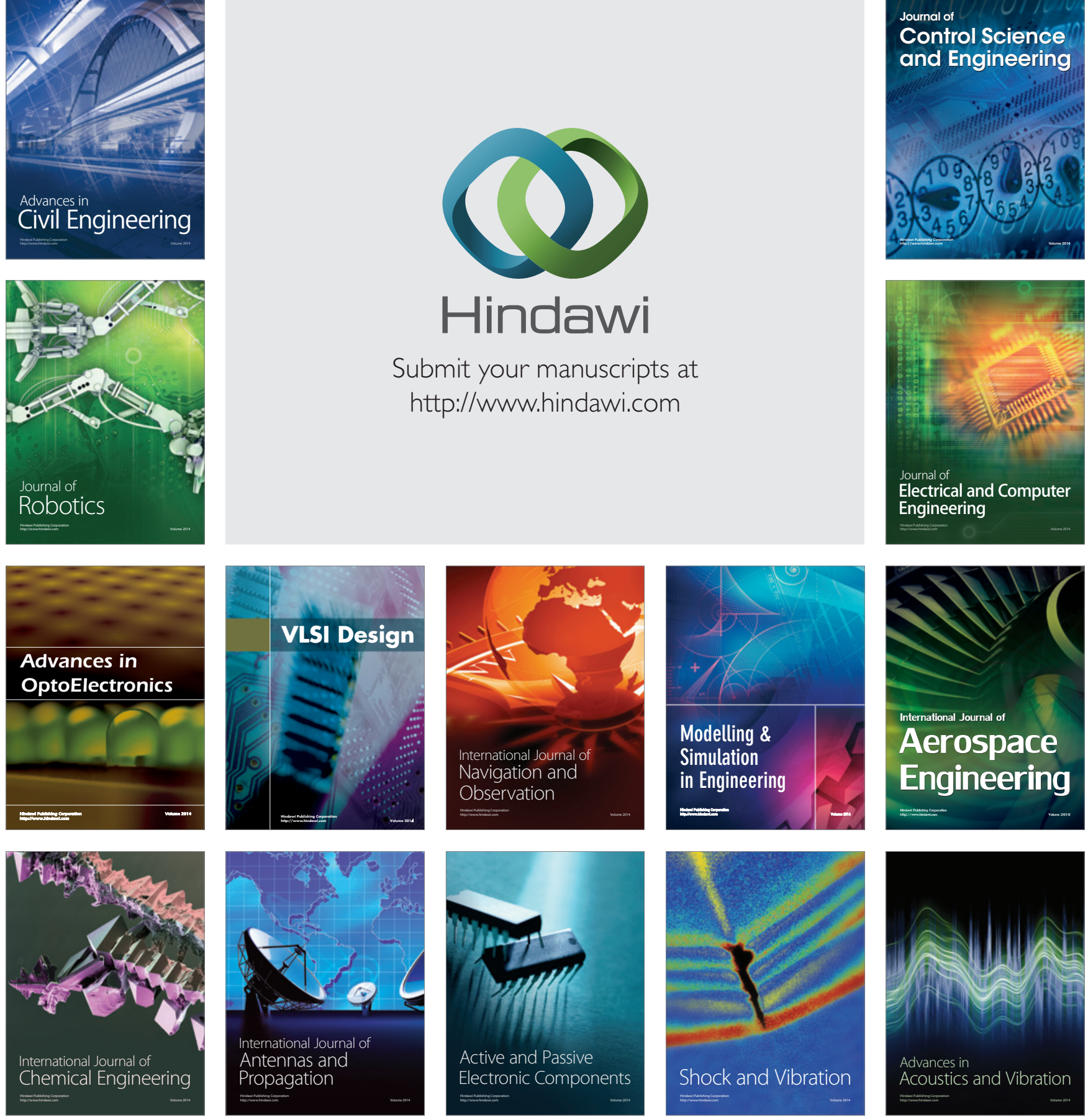